\title{
The pathology of the early and late stages of primary pulmonary hypertension
}

\author{
DONALD HEATH, PAUL SMITH, JOHN GOSNEY, DAVID MULCAHY, * \\ KIM FOX, * MAGDI YACOUB, $\dagger$ PETER HARRIS* \\ From the Department of Pathology, University of Liverpool; ${ }^{\star}$ National Heart Hospital, London; and \\ †Harefield Hospital, London
}

SUMMARY During the course of a case of primary pulmonary hypertension occurring in a 24 year old man lung tissue became available at heart-lung transplantation in 1986 and from a lung biopsy carried out in 1981. In 1986 the sections showed classic plexogenic pulmonary arteriopathy. In 1981 they revealed migration of myofibroblasts into the intima and lumen of pulmonary arteries and arterioles, the identification of the cells being confirmed by electron microscopy. During the five years that the pulmonary vascular pathology progressed to the formation of plexiform lesions there was an increase in the number of bronchiolar endocrine cells that were immunoreactive to bombesin and calcitonin.

This study demonstrates that the classic pathogenesis of primary plexogenic pulmonary arteriopathy originates years earlier as a migration of cells of muscular pedigree from the media into the intima of the pulmonary arteries and arterioles.

The histological features of fully developed plexogenic pulmonary arteriopathy, which forms the pathological basis for primary pulmonary hypertension, are well known. We have recently described them in detail together with the less familiar ultrastructural characteristics. ${ }^{1}$ There is much less information on the histological and ultrastructural features of the early stages of the disease before the appearance of the plexiform lesions, fibrinoid necrosis, and "onion-skin proliferation" in pulmonary arteries. Yet this early stage is of great interest to the pathologist because familiarity with its features will enable him to diagnose with more confidence plexogenic pulmonary arteriopathy before the plexiform lesions develop. As the term implies, every case need not have plexiform lesions-only the potential to develop them. The early stage is also of prime interest to the clinician since analysis of the initial pathological lesions may suggest to him which treatment, if any, is likely to alleviate or even reverse the condition before it progresses to the fully developed dis-

Requests for reprints to Professor Peter Harris, National Heart Hospital, Westmoreland Street, London W1M 8BA.

Accepted for publication 31 March 1987 ease for which heart-lung transplantation is the only treatment.

The difficulty has been that in most early cases of primary pulmonary hypertension the histopathologist has to assume without proof that the lesions he is describing will progress to classic plexogenic pulmonary arteriopathy. It is unusual to be able to study the pulmonary vascular lesions at an early stage in an individual case in which there is unequivocal progression of the lesions to the immediately recognisable disease and to have the opportunity to study lung tissue removed at heart-lung transplantation. For this reason we thought it was worth while to report the histological findings in such a case in which the observations were separated by a period of five years. The case is of added interest in demonstrating for the first time that primary plexogenic pulmonary arteriopathy may be associated with abnormal numbers of cells that are immunoreactive for certain peptides in the epithelium of the bronchial tree.

\section{Case report}

The patient was a paint sprayer. In 1980 , at the age of 18 years, cardiomegaly was found at routine mass $x$ ray. He had no symptoms at that time. A cardiac 
murmur had been noted in infancy but his parents had been advised that he would "grow out of it". Throughout childhood and adolescence he had been free from cardiac symptoms. On admission to hospital the pulse was regular at 80 beats/minute. The jugular venous pressure was normal and the systemic blood pressure $130 / 80 \mathrm{~mm} \mathrm{Hg}$. There was a slight prominence of the left chest. At the left sternal border there was an ejection click, a grade $1 / 6$ ejection systolic murmur, fixed splitting of the second sound, and a grade $2 / 6$ early diastolic murmur. The radiograph of the chest showed dilatation of the pulmonary trunk and its main branches (fig 1a). The electrocardiogram showed right ventricular hypertrophy. At cardiac catheterisation the pulmonary arterial pressure was $70 / 24 \mathrm{~mm} \mathrm{Hg}$. There was no evidence of a shunt. A pulmonary angiogram demonstrated a considerable enlargement of the pulmonary trunk and its major divisions. There was some reflux across the pulmonary valve. The right ventricle was enlarged but the left atrium and ventricle appeared normal. A lung scan showed some underperfusion of the middle and upper zones that was not thought to be suggestive of pulmonary embolisation. Respiratory function tests were normal. A diagnosis of primary pulmonary hypertension was made. He was treated with hydralazine. In 1981 a biopsy specimen of the lung was taken. In 1983 he complained of occasional pains in the chest and treatment was changed to nifedipine. At that point he became lost to follow up.

In November 1985 he was again admitted to the Leeds General Infirmary. He had had increasing dyspnoea on exertion for six months. More recently he had developed precordial pain on exertion and swelling of the ankles. On three occasions he had lost consciousness during exertion. He was taking $10 \mathrm{mg}$ nifedipine three times a day together. with diuretics. There was oedema of the legs. The jugular venous pressure was raised $5 \mathrm{~cm}$ with prominent " $a$ " waves. The systemic arterial pressure was $90 / 70 \mathrm{~mm} \mathrm{Hg}$. The heart was enlarged with a prominent systolic outward movement of the entire precordium. A fourth sound was present, together with a loud second and an ejection click, grade $4 / 6$ ejection systolic murmur, and grade 3/4 diastolic murmur at the left border of the sternum. The liver was palpable $5 \mathrm{~cm}$ below the costal margin. He was jaundiced. The chest radiograph showed enlargement of the heart and considerable dilatation of the pulmonary trunk and its primary and proximal branches (fig $1 \mathrm{~b}$ ). The electrocardiogram indicated severe right ventricular hypertrophy. Echocardiography confirmed dilatation of the right ventricle and right atrium.

He was assessed and accepted for cardiopulmonary transplantation at the National Heart Hospital and sent back to Leeds to await operation. Within two months, however, he developed severe generalised oedema and ascites with increasing renal and hepatic failure. A hepatic biopsy specimen

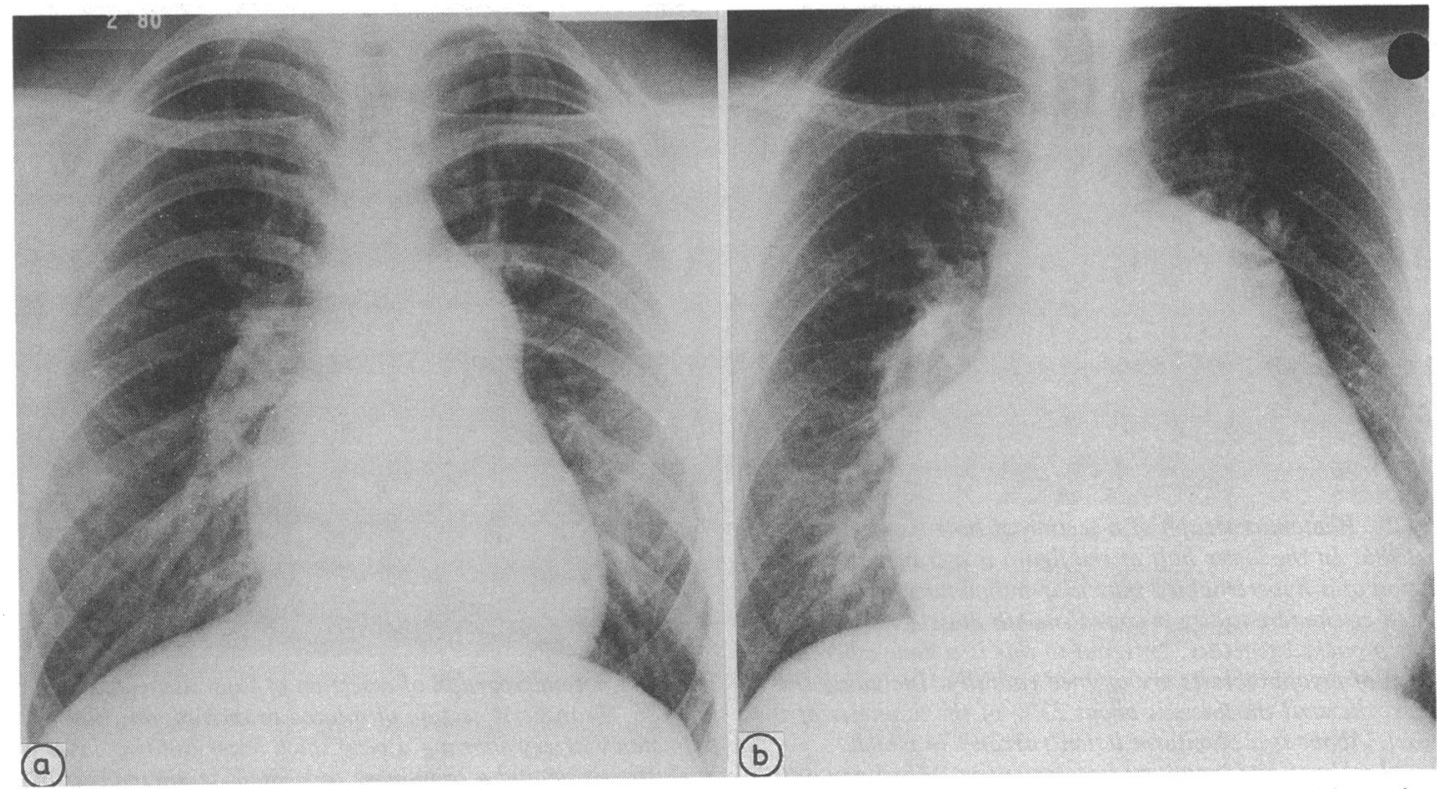

Fig 1 Chest radiographs obtained in 1980 (a) and 1986 (b). (a) Shows dilatation of the pulmonary trunk and its main branches. The aortic arch appears small. The cardiothoracic ratio was 1:2. (b) The dilatation of the pulmonary trunk and its proximal branches has progressed and considerable cardiac enlargement has developed. 
showed evidence of severe venous congestion but no underlying chronic liver disease. Intensive treatment with albumin infusions and diuretics produced some amelioration before transplantation was attempted. He did not regain consciousness after the operation, although cardiopulmonary function was adequate.

\section{Pulmonary vascular pathology in 1986}

The histological features of the lung resected at heart-lung transplantation were typical of advanced plexogenic pulmonary arteriopathy. The elastic pulmonary arteries showed severe atherosclerosis. There was gross intimal proliferation of atherosclerotic tissue which had penetrated through the internal elastic lamina deep into the underlying media where it replaced the existing musculoelastic tissues. There was severe medial hypertrophy of the muscular pulmonary arteries; the total wall thickness was some $25 \%$ of the external diameter (fig 2).

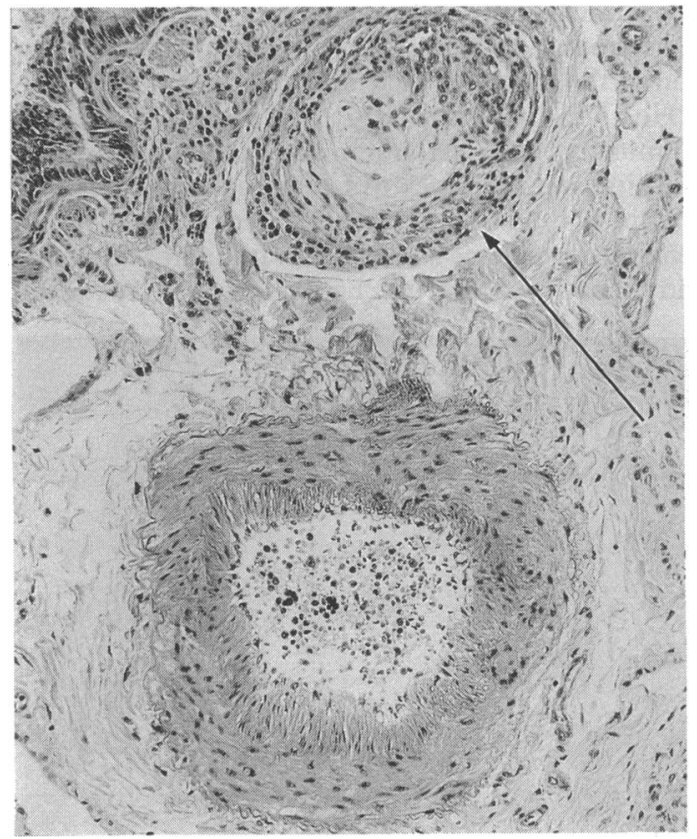

Fig 2 Photomicrograph of a section of lung tissue obtained in 1986. In the lower half of the figure is a transverse section of a hypertrophied muscular pulmonary artery in which circumferentially oriented smooth muscle cells are tightly packed together. Internal to this is a zone where the nuclei of myofibroblasts are aligned radially. Including this layer, the wall thickness is about $25 \%$ of the diameter of the vessel. Above is a plexiform lesion (arrow) in which myofibroblasts and primitive vasoformative "fibrillary cells" have proliferated inside a dilated branch of the hypertrophied parent artery. (Haematoxylin and eosin; $\times$ 140.)
Sections stained with haematoxylin and eosin showed the compact media to be composed of circumferentially orientated smooth muscle cells with an inner layer of myofibroblasts whose nuclei were arranged radially (fig 2). Sections stained with an elastic van Gieson stain demonstrated the hypertrophied media delineated by inner and outer elastic laminae. This staining technique revealed that the inner zone of radially arranged myofibroblasts had formed a layer of musculoelastic tissue. This prominent layer of concentric-laminar musculoelastic tissue in the intima extended into many of the branches of the muscular pulmonary arteries where it considerably reduced the lumen (fig 3 ). In this layer the muscle cells were prominent and well defined and the elastic tissue was arranged as thick, well defined laminae (fig 3).

Plexiform lesions were much in evidence (fig 2). In sections stained by haematoxylin and eosin they appeared as dilated branches of muscular pulmonary arteries in which there had been a proliferation of cells, which we know from previous ultrastructural studies to be a mixture of myofibroblasts and primitive vasoformative reserve cells previously termed

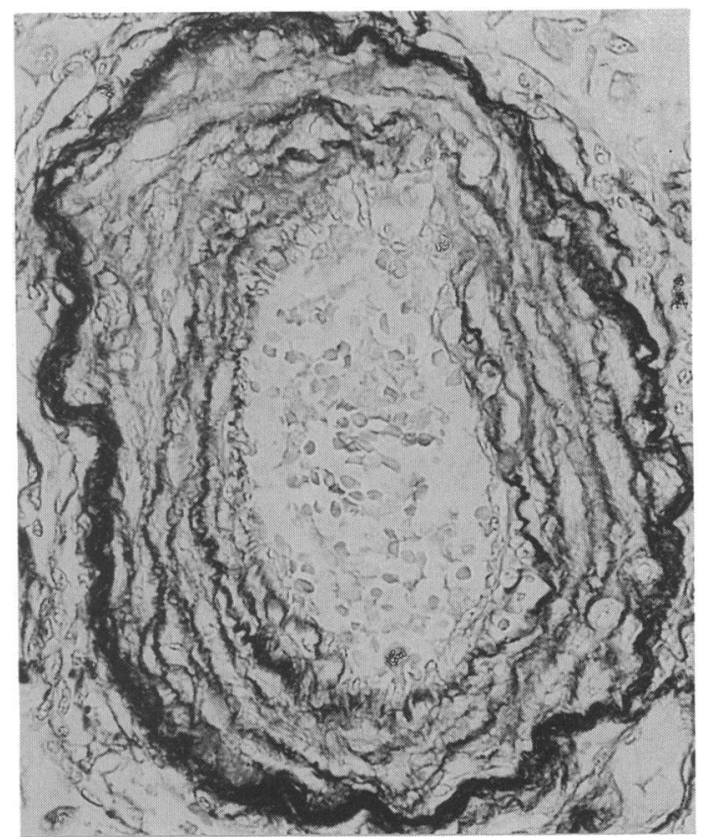

Fig 3 Photomicrograph of a section of lung tissue obtained in 1986. Transverse section of dilated branch of muscular pulmonary artery showing a very thick outer limiting layer of elastic tissue and a prominent concentric-laminar layer of musculo-elastic tissue. Within this layer the elastic fibrils are thick and well defined. The muscle layers are prominent. (Elastic van Gieson; $\times$ 450.) 
"fibrillary cells. ${ }^{2}$ In sections stained by the elastic van Gieson technique the limiting remains of the media of the dilated branch of the muscular pulmonary artery could be made out (fig 4). Some plexiform lesions arose as side-branches of the largest muscular pulmonary arteries which showed severe intimal fibroelastosis. Many of the small muscular pulmonary arteries showed concentric-laminar ("onion-skin") intimal proliferation (fig 5). A few showed subacute necrotising arteritis with replacement of lengths of media by fibrous tissue as part of a process of repair of necrotic media. There were small focal collections of siderophages in the alveolar spaces; these had probably resulted from haemorrhage from thin-walled branches of muscular pulmonary arteries.

\section{Pulmonary vascular pathology in 1981}

The histological features of the lung-biopsy specimen resected in 1981 differed in important respects from the picture of classic plexogenic pulmonary arteriopathy found in 1986 and described above. At that time the muscular pulmonary arteries already showed pronounced medial hypertrophy, the medial

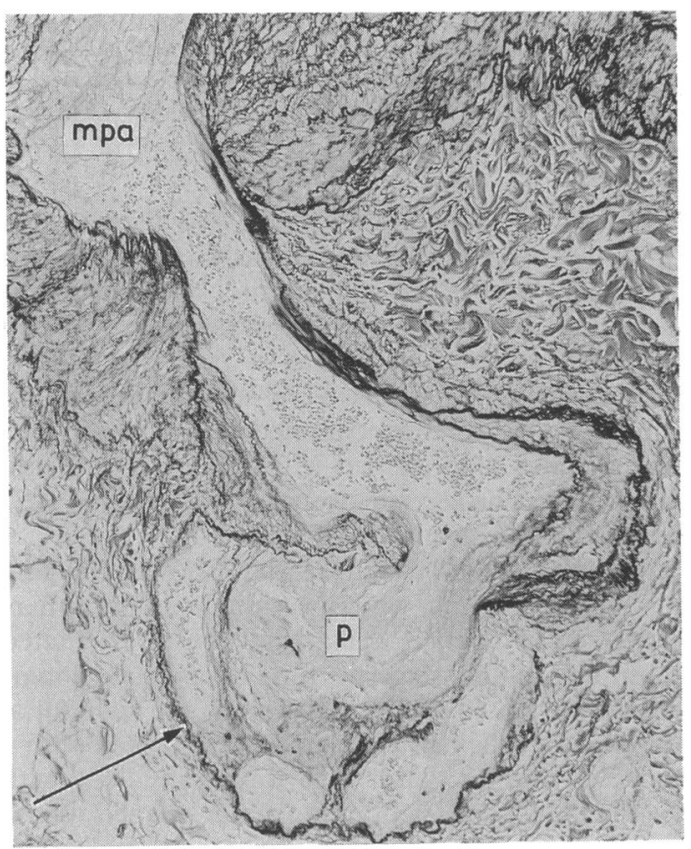

Fig 4 Photomicrograph of a section of lung tissue obtained in 1986. Plexiform lesion ( $p$ ) arising as a side-branch of a large muscular pulmonary artery (mpa) which itself shows prominent fibroelastic tissue. The remaining elastic tissue delineates the outer margin of the plexiform lesion (arrow). (Elastic van Gieson; $\times 135$.)

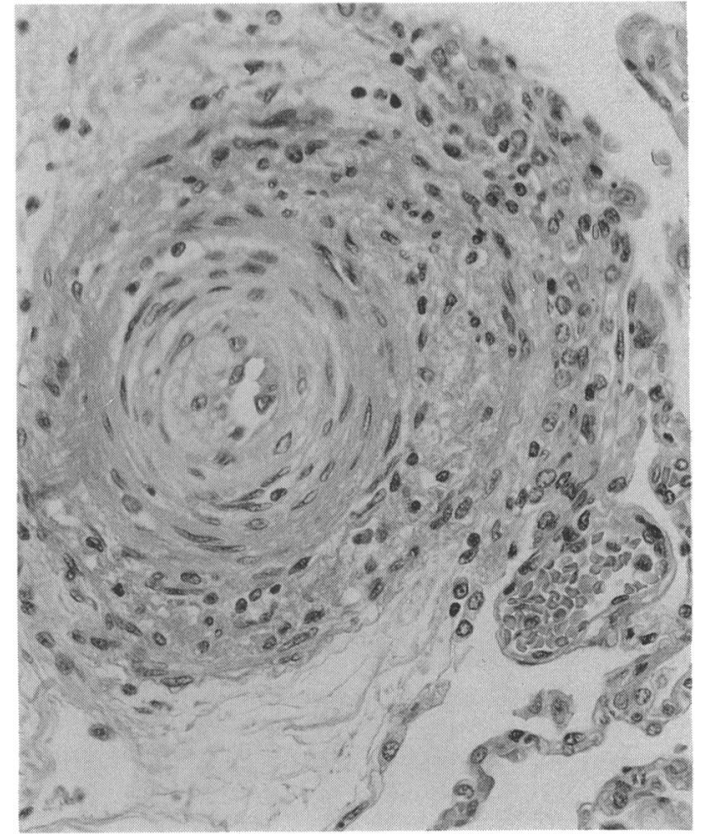

Fig 5 Photomicrograph of a section of lung tissue obtained in 1986. Transverse section of a small, muscular pulmonary artery showing concentric-laminar ("onion-skin") proliferation of myofibroblasts. (Haematoxylin and eosin; $\times$ 350.)

thickness approaching $15 \%$ of the external diameter of arteries which were around $270 \mu \mathrm{m}$ in diameter (fig 6). The muscular pulmonary arteries had thick inner and outer elastic laminae which were in part crenated. Wispy elastic fibrils were seen in the substance of the media. In some of the larger muscular pulmonary arteries there were fasciculi of longitudinal smooth muscle in the outer media at its interface with adventitia; in others there were eccentric bundles of musculoelastic tissue in the intima. In other muscular pulmonary arteries there were crescentic areas of intimal elastic tissue (fig 6). Some of their branches were almost blocked by concentric-laminar intimal elastosis (fig 7) that resembled the changes seen in the lung five years later. In the lesions seen in 1981 the elastic fibrils were wispy and ill-defined (fig 7) compared with those seen in a similar situation five years later when the elastic fibrils were thicker, and well defined (fig 3). The parent elastic pulmonary arteries appeared normal with thick concentric elastic laminae embedded in the media of smooth muscle.

In the lung biopsy material resected in 1981 there was no intimal concentric-laminar ("onion-skin") proliferation, no fibrinoid necrosis, or necrotising arteritis, and, above all, no plexiform lesions. In the 


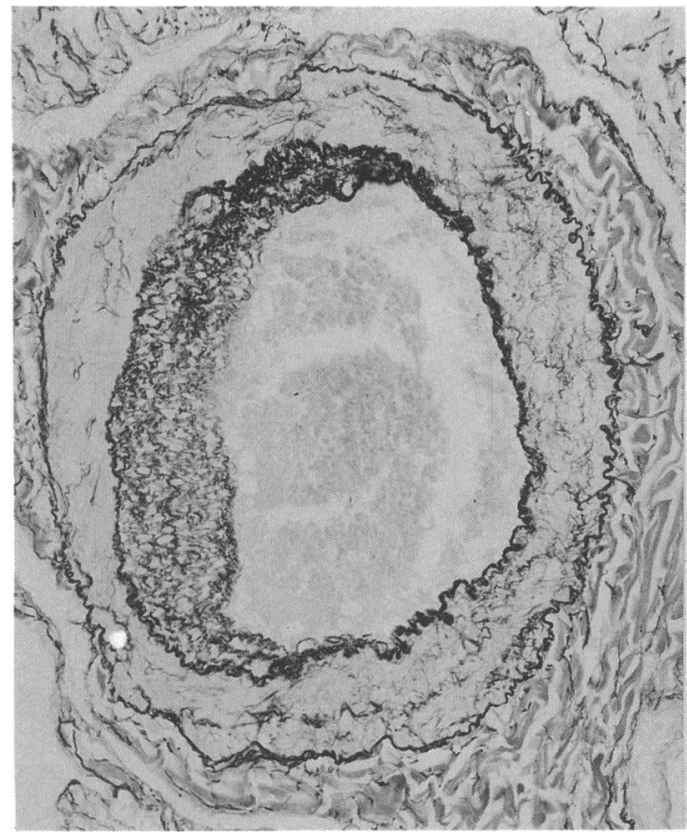

Fig 6 Photomicrograph of a section of lung tissue obtained in 1981. Transverse section of muscular pulmonary artery showing medial hypertrophy; the thickness of the media was variable but averaged out at $15 \%$ of the external diameter of the vessel. There is a large crescentic mass of intimal fibroelastosis. (Elastic van Gieson; $\times 225$.)

earlier lung tissue, however, there were important lesions in the small muscular pulmonary arteries, pulmonary arterioles, and precapillaries. These took the form of a proliferation into the lumen of elongated cells with spindle-shaped nuclei that stained yellow with van Gieson's stain (fig 8). They had the cytological features of myofibroblasts. Loosely arranged in the lumen of the arterioles in a filigree pattern they maintained contact by many slender, elongated processes with the elastic lamina that made up the wall of the arteriole. In some instances there was migration of the myofibroblasts through the elastic wall of the pulmonary arteriole (fig 8). Both arterioles and precapillaries were packed with myofibroblasts. There was no intimal proliferation of any type in the pulmonary veins.

\section{Electron microscopy}

The lung biopsy specimen in 1981 was received fixed in formol saline, which is not ideal for electron microscopy. Nevertheless, small fragments of lung tissue were taken and processed for ultrastructural study. They were washed in buffer solution and

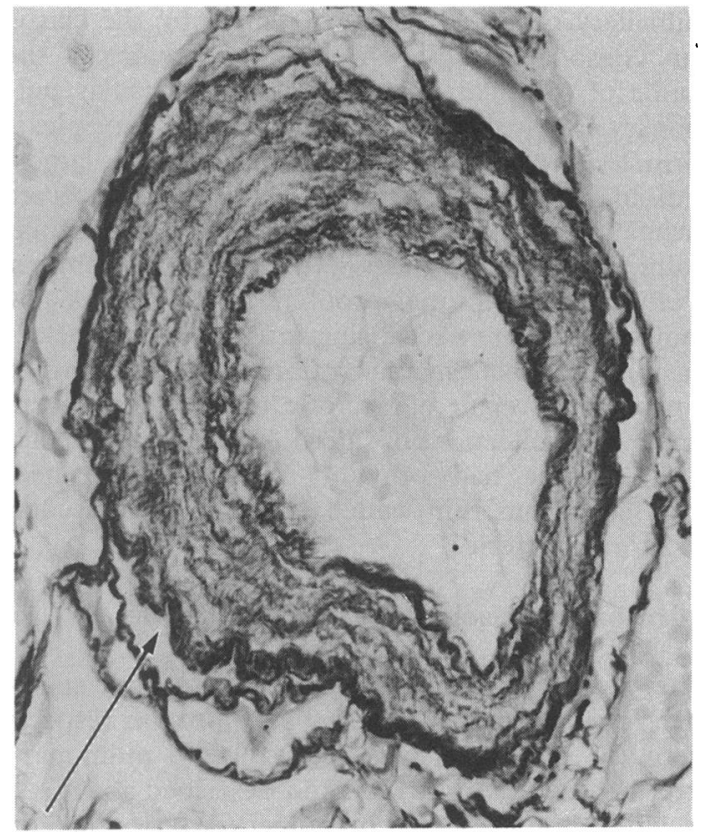

Fig 7 Photomicrograph of a section of lung tissue obtained in 1981. Transverse section of thin-walled branch of muscular pulmonary artery whose wall is composed of a thick elastic lamina. The remains of the muscular media of the parent artery are indicated by an arrow. There is a thick layer of concentric-laminar intimal elastosis. (Elastic van Gieson; $\times$ 540.)

fixed first in $3 \%$ glutaraldehyde and then in $1 \%$ osmium tetroxide. The tissue was then dehydrated in ethanol, embedded in Araldite, and stored for future use. Sections $1 \mu \mathrm{m}$ in thickness were stained with toluidine blue and areas of tissue containing pulmonary blood vessels were selected for study. The blocks were then trimmed and fine sections were cut and then stained with uranyl acetate and lead citrate. The sections were studied with an AEI Corinth 500 electron microscope.

Muscular pulmonary arteries showed hypertrophy of the media, which was made up of numerous smooth muscle cells that were orientated circumferentially except for occasional longitudinally oriented groups adjacent to the adventitia. The muscle cells had elongated nuclei, often with a crenated outline, and a cytoplasm filled with myofilaments and containing cigar-shaped dense bodies, the so-called "focal condensations". The periphery of the smooth muscle cells bore numerous, dark attachment points interspersed with paler regions containing micropinocytotic vesicles. In some areas medial smooth muscle cells adjacent to the internal elastic lamina had adopted a radial ori- 


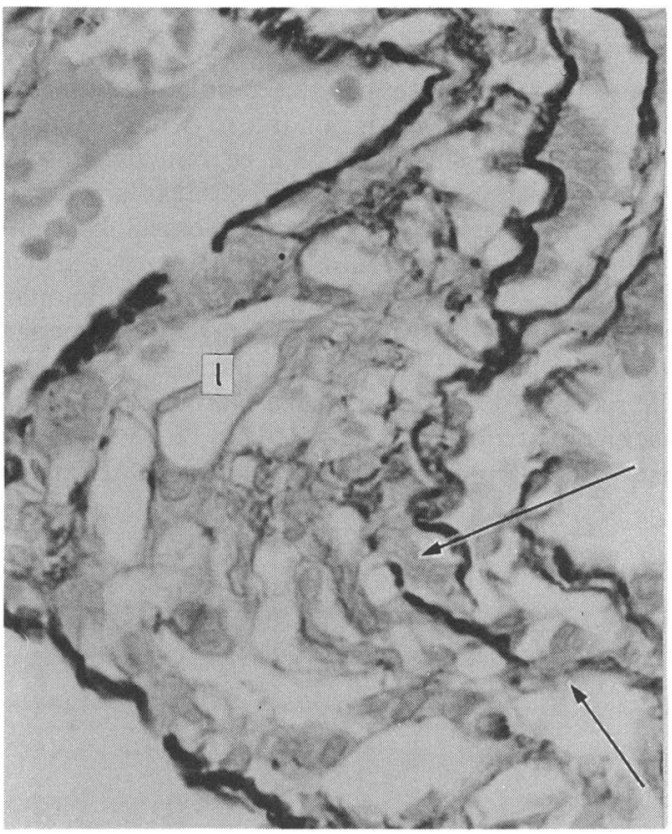

Fig 8 Photomicrograph of a section of lung tissue obtained in 1981. Longitudinal section of pulmonary arteriole showing migration of myofibroblasts into the lumen (l). Sites where the cells are traversing elastic laminae are indicated by arrows. The cells have an irregular, elongated shape. (Elastic van Gieson; $\times$ 938.)

entation as though migrating towards the intima (fig 9). In no instance were we able to demonstrate a muscle cell actually penetrating the elastic lamina, although this appearance was seen in the histopathological sections. Inside the inner lamina there were proliferating cells in the intima with ultrastructural features such as myofilaments and focal condensations that showed their muscular pedigree (fig 10). The intercellular spaces contained finely fibrillary ground substance, numerous collagen fibres (fig 9), and small deposits of immature elastin (fig 10). In view of their obviously secretory function we prefer to call the cells in the intima, "myofibroblasts". The fragmented internal elastic lamina was largely obscured by the profusion of collagen fibres and immature elastin.

Pulmonary arterioles showed the same intense proliferation of myofibroblasts in the intima but in these vessels the cells were much paler than their arterial counterparts and contained fewer myofilaments and focal condensations. In some myofibroblasts there was cytoplasmic vacuolation and disruption of mitochondria. This may have been an artefact caused by the initial slow formalin fixation. There was less intercellular ground sub- stance and collagen in pulmonary arterioles than in muscular pulmonary arteries and there was very little elastin. The intimal myofibroblasts were separated from the endothelium by only a narrow basement membrane. Endothelial cells were compressed and displaced towards the lumen but were otherwise normal. They were readily identified because of the numerous Weibel-Palade bodies they contained. Myofibroblasts were also encountered in terminal arterioles which approached the size of precapillaries. In these small vessels they did not form a continuous intimal layer but rather a series of small pads projecting into the lumen. These cells were also pale and contained few myofilaments.

\section{Pulmonary endocrine cells}

Sections of lung were cut at $4 \mu \mathrm{m}$ and labelled by the peroxidase-antiperoxidase method ${ }^{3}$ with polyclonal primary antisera raised in rabbit to human neuronspecific enolase and calcitonin, bombesin, and leucine-enkephalin. The chromogen used was 3-amino-9-ethyl carbazole which gives a red-brown precipitate. We assessed the numbers of immunoreactive cells containing each of the peptides under study by counting their number and expressing it per square centimetre of tissue section as determined by planimetry, because the pulmonary tissue was collapsed. This method has been used successfully in previous studies. ${ }^{45}$

The cytology, histology, and distribution of endocrine cells in the pulmonary tissue from 1981 showed no abnormal features. Cells containing calcitonin and bombesin were scattered throughout the airways, occurring predominantly as solitary cells and occasionally as clusters. We did not find cells that were immunoreactive for leucine-enkephalin. All were immunoreactive for neuron-specific enolase, but none was argyrophilic irrespective of whether they contained calcitonin or bombesin. No cells containing calcitonin or bombesin were identified in the alveolar ducts or alveoli. In the three blocks of tissue examined (total sectional area $3.65 \mathrm{~cm}^{2}$ ) there were 3.3 cells per $\mathrm{cm}^{2}$ that were immunoreactive for calcitonin and 9.0 cells per $\mathrm{cm}^{2}$ that were immunoreactive for bombesin. The largest cluster seen contained five cells in one plane of section.

The appearance of the endocrine cells in the pulmonary tissue from 1986 was quite different. Cells containing calcitonin (fig 11) and bombesin (fig 12) were aggregated into clusters of variable size. In addition, the number of solitary endocrine cells containing these peptides was increased. Some of the clusters clearly consisted of aggregates of solitary cells and bore little resemblance to the normal 
neuroepithelial body. Two further features were notable. In some of the aggregates there was costorage of bombesin and calcitonin. In others, the component cells were argyrophilic. As in the tissue from 1981, no cells that were immunoreactive for leucine-enkephalin were identified but all those containing bombesin or calcitonin or both were immunoreactive for neuron-specific enolase. No endocrine cells were identified in alveolar ducts or alveoli. In the four blocks of tissue examined, which made up a total sectional area of $10.85 \mathrm{~cm}^{2}$, there were $21 \cdot 2$ cells per $\mathrm{cm}^{2}$ that were immunoreactive for calcitonin and 50 cells per $\mathrm{cm}^{2}$ that were immunoreactive for bombesin.

\section{Discussion}

There are many causes of a raised pulmonary arterial pressure and usually it is possible to demonstrate the basis of its development. There remains a small group of patients with clinically unexplained pulmonary hypertension. The pathological basis for pulmonary hypertension in these patients is usually plexogenic pulmonary arteriopathy, pulmonary veno-occlusive disease, or recurrent pulmonary thromboembolism. ${ }^{1}$ A fourth pathological entity, the recently described invasive pulmonary capillary haemangiomatosis, ${ }^{6-8}$ may need to be added to this list, although here the characteristic recurrent

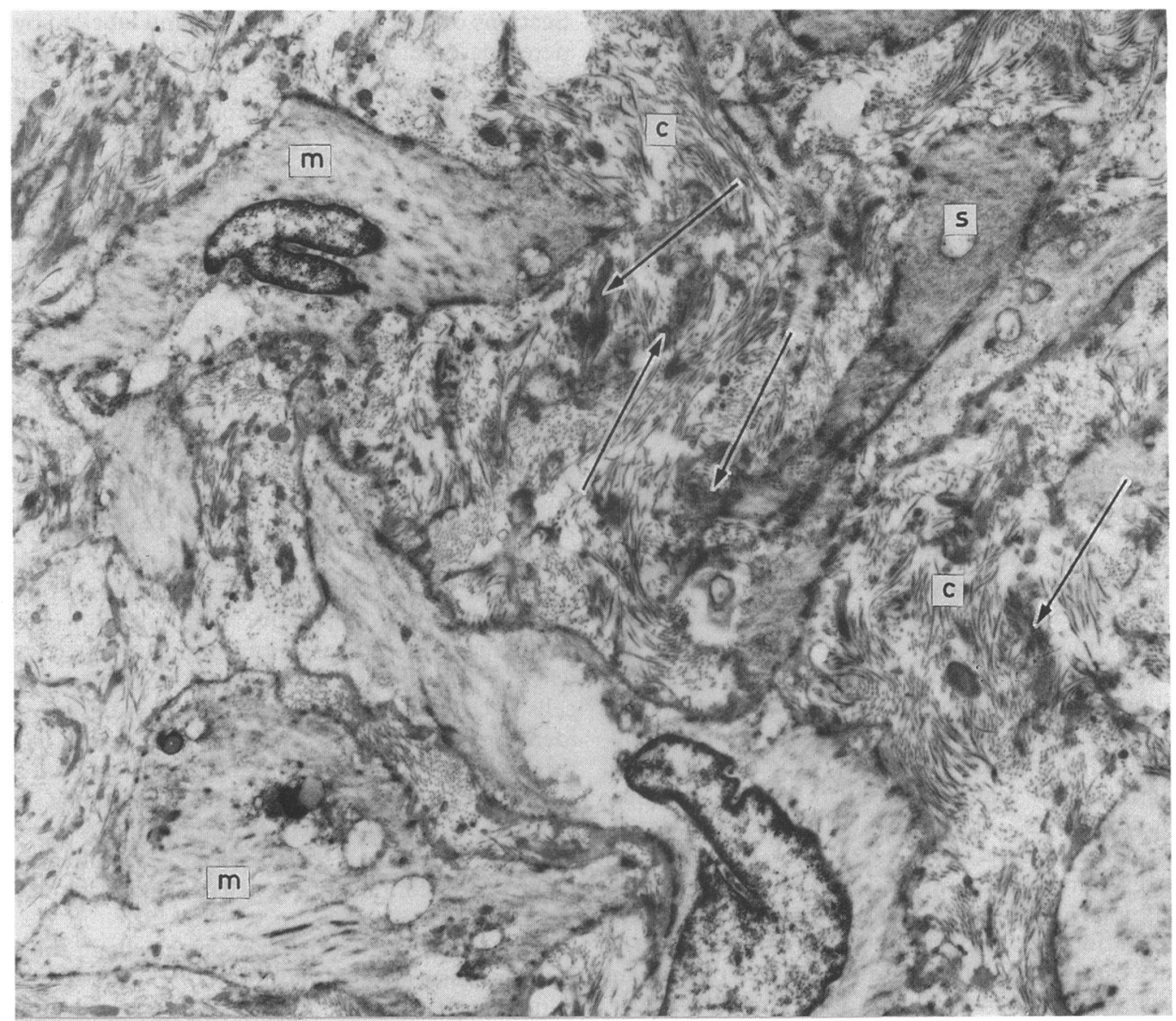

Fig 9 Electron micrograph (tissue obtained in 1981) of part of the wall of a muscular pulmonary artery at the junction of media and intima. The internal elastic lamina is indistinct and consists of small, dark fragments of elastic tissue (arrowed) separated by an extensive network of collagen fibres (c). Smooth muscle cells (s) in the media are orientated at right angles to the lamina and extend into it. The intima contains myofibroblasts ( $m$ ), which are similar to smooth muscle, and sparsely distributed collagen fibres. $(\times 7000$.) 
haemoptysis may allow clinical diagnosis. Commonly, however, clinical examination and investigation will not distinguish one condition from the other and an open lung biopsy is needed for precise diagnosis.

Plexogenic pulmonary arteriopathy, a term designated by a Working Party of the World Health Organisation ${ }^{9}$ is not specific to primary pulmonary hypertension but also occurs in cases of pre- and post- tricuspid congenital cardiac shunt such as atrial and ventricular septal defect, ${ }^{1}$ and of severe pulmonary hypertension complicating cirrhosis of the liver or portal vein thrombosis. ${ }^{10}$ The feature which distinguishes this pathological entity in pri- mary pulmonary hypertension is that it occurs on its own as primary plexogenic pulmonary arteriopathy.

The words of the designation of the disease were carefully chosen. Each case has the potential for forming plexiform lesions but they may not be present in any individual case. They take time to develop. The plexiform lesion is a dilated branch of a muscular pulmonary artery in which a plexiform mass of narrow vascular channels and cells forms. ${ }^{1}$ The proliferation appears to be a response to fibrin and fibrinoid material derived from the media of the parent muscular pulmonary artery. ${ }^{11}$ Our own electron microscopical studies ${ }^{2}$ have shown that the vascular channels are not true capillaries since they are

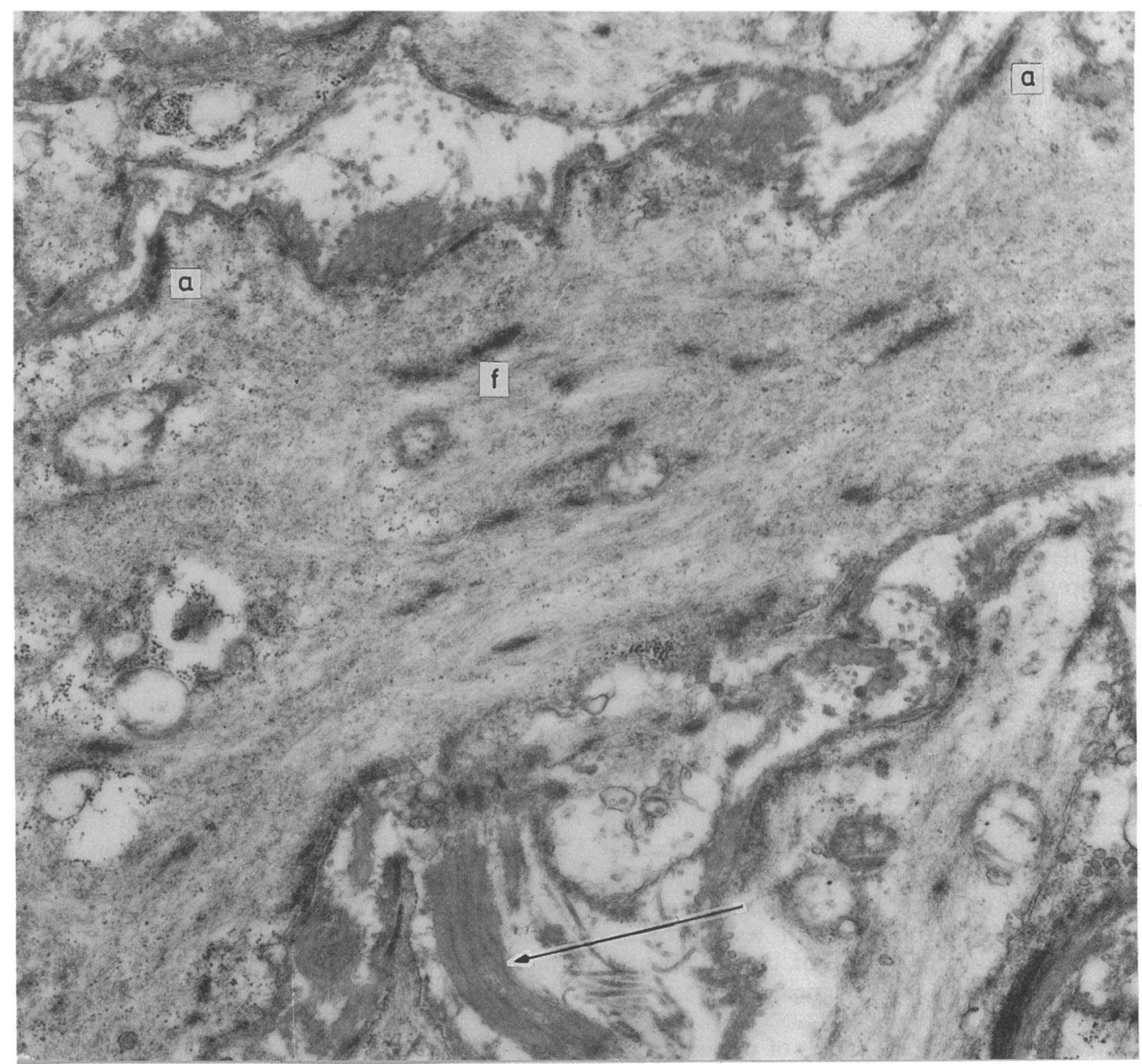

Fig 10 Electron micrograph (tissue obtained in 1981) showing detail of a myofibroblast from an area of intimal elastosis in a muscular pulmonary artery. The cell contains numerous myofilaments, focal condensations $(f)$, and peripheral attachment points (a). The intercellular space contains collagen fibrils and immature elastin (arrow). $(\times 17500$. 


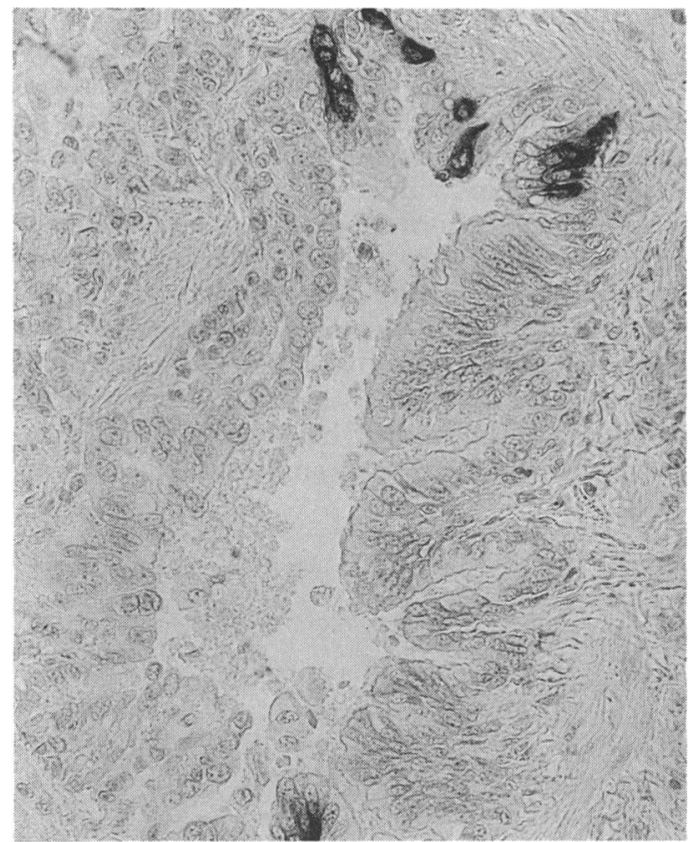

Fig 11 Photomicrograph of a section of lung tissue obtained in 1986. Transverse section of small bronchiole showing cells immunoreactive for calcitonin in the bronchiolar mucosa. (Peroxidase-antiperoxidase; $\times 350$.)

lined not by endothelial cells but by primitive vasoformative cells which we have called "fibrillary cells". The cytoplasm of these cells contains numerous microfilaments of uniform thickness arranged in whorls. ${ }^{2}$ Between the vascular channels is a matrix of acid proteoglycans in which myofibroblasts and fibrillary cells are embedded. One associated histological lesion is concentric-laminar proliferation of cells ("onion-skin proliferation") in muscular pulmonary arteries or their branches; the cells which proliferate have been shown to be myofibroblasts. $^{2}$ Another is fibrinoid necrosis of the media of the parent artery in which fibrin and related substances may be released into dilated branches and stimulate the formation of plexiform lesions; the fibrinoid necrosis will also attract neutrophil polymorphs and thus give the picture of necrotising arteritis. When this characteristic triad of histological lesions occurs together in an advanced stage of plexogenic pulmonary arteriopathy the diagnosis is easy and straightforward.

The features of the early stages of proven plexogenic pulmonary arteriopathy are far less familiar and so the findings in the present case are of special interest. In this young man severe pulmonary vascular disease was already established five years before

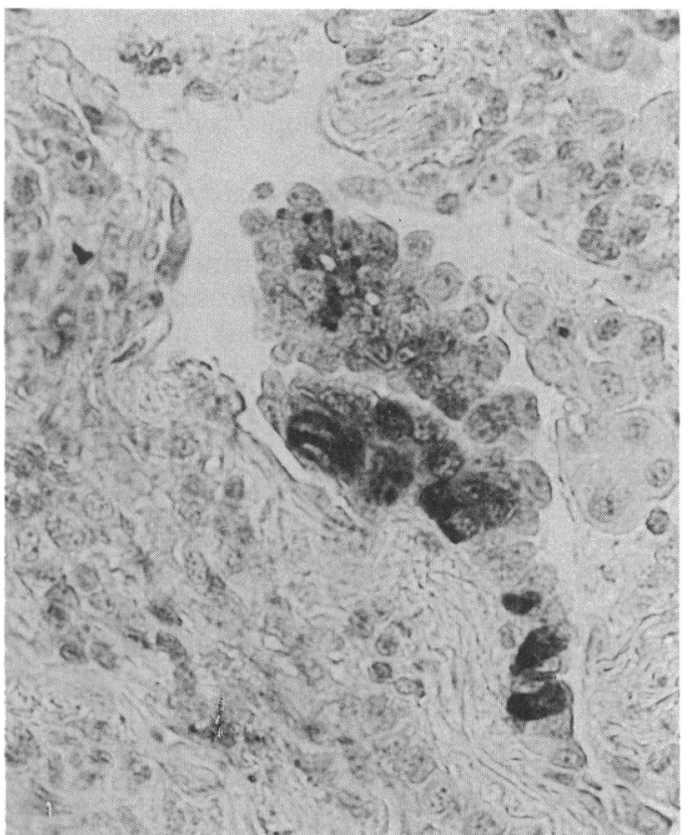

Fig 12 Photomicrograph of a section of lung tissue obtained in 1986 showing a group of cells lining a small bronchiole that are immunoreactive for bombesin. (Peroxidase-antiperoxidase; $\times 562$.)

plexiform lesions were found in lung tissue resected at heart-lung transplantation, and one year later cardiomegaly was noted at mass $x$ ray when the patient was free from symptoms. The initial vascular lesions included prominent medial hypertrophy indicative of a considerable increase in pulmonary arterial pressure and resistance as early as 1981 and this is consistent with the haemodynamic findings at that time. The second important component of the disease process at that time was a migration of cells from the media of muscular pulmonary arteries into the intima of the vessels and their branches. Electron microscopy demonstrated that these cells were myofibroblasts; so the striking proliferations of intimal elastosis and musculoelastosis in the pulmonary arteries (fig 6) and their branches (fig 7) were the result of formation of connective tissues of various types by cells of a muscular pedigree. The migration, proliferation, and secretory activity of these cells appeared to persist for years since the intimal muscularity and elastosis was still present in the lung tissue resected in 1986, albeit with certain changes such as the thickening and sharper modelling of the elastic fibres.

Myofibroblasts also migrated through deficiencies in the inner elastic lamina of the pulmonary arte- 
rioles, leading to occlusion of the lumen. Such appearances indicate that the early stage of plexogenic pulmonary arteriopathy is characterised by a hyperplasia of cells of muscular pedigree. Primary pulmonary hypertension is traditionally described as a vasospastic form of pulmonary vascular disease and the later stages of its pathology with fibrinoid necrosis are certainly consistent with that view. However, the earliest stages appear to be an active migration of muscle cells and this seems to have implications for treatment of the early stages of the disease because it is difficult to see how the administration of pulmonary vasodilators could influence this migration of muscle-derived cells to block the vascular lumen.

The stimulus for the migration of the myofibroblasts is obscure but in the present case there was evidence of increased immunoreactivity in the bronchiolar epithelial cells for both calcitonin and bombesin. Pulmonary endocrine cells containing these regulatory peptides were present in normal numbers in the lung tissue from 1981 but had increased by 1986 . The content of bombesin in particular was abnormally high. It is traditional in defining primary pulmonary hypertension to state that the lung per se beyond the pulmonary vasculature is normal. The findings in the present case make it clear that this is not true. In this case there was unequivocal evidence of increased immmoreactivity for calcitonin and, especially, bombesin. At present it is difficult to see how increased secretions of regulatory peptides in the bronchial tree could induce proliferation and migration of the myofibroblasts in the pulmonary arteries. It seems that the stimulus for growth of the muscle cells would be more likely to originate in the closely adjacent endothelial cells. This aspect of the pathology of plexogenic pulmonary arteriopathy clearly requires further investigation.

This study was part of a scheme of research funded by a grant from the British Heart Foundation to $\mathrm{DH}, \mathrm{PH}$, and $\mathrm{MY}$.

\section{References}

1 Harris P, Heath D. The human pulmonary circulation. Its form and function in health and disease. 3rd ed. Edinburgh: Churchill Livingstone, 1986.

2 Smith P, Heath D. Electron microscopy of the plexiform lesion. Thorax 1979;34:177-86.

3 Sternberger LA. The unlabelled antibody peroxidaseantiperoxidase (PAP) method. In: Sternberger LA, ed. Immunocytochemistry. New York: John Wiley, 1979:104-69.

4 Taylor W. Pulmonary argyrophil cells at high altitude. J Pathol 1977;122:137-44.

5 Sissons MCJ, Gosney JR. Pulmonary endocrine cells immunoreactive for calcitonin in the lungs of fetal and neonatal rats. Thorax 1985;40:862-5.

6 Wagenvoort CA, Beetstra A, Spijker J. Capillary haemangiomatosis of the lungs. Histopathology 1978;2:401-6.

7 Whittaker JS, Pickering CAC, Heath D, Smith P. Pulmonary capillary haemangiomatosis. Diagnostic Histopathology 1983;6:77-84.

8 Heath D, Reid R. Invasive pulmonary haemangiomatosis. Br J Dis Chest 1985;79:284-94.

9 Hatano S, Strasser T, eds. Primary pulmonary hypertension. Report on a WHO meeting, Geneva, October 1973. Geneva: World Health Organisation, 1975.

10 Saunders JB, Constable TJ, Heath D, Smith P, Paton A. Pulmonary hypertension complicating portal vein thrombosis. Thorax 1978;34:281-3.

11 Wagenvoort CA. The morphology of certain vascular lesions in pulmonary hypertension. J Pathol Bacteriol 1959;78:503-11. 